\title{
A grounding physicalist solution to the causal exclusion problem
}

\author{
Robin Stenwall ${ }^{1,2}$
}

Received: 12 September 2019 / Accepted: 7 August 2020 / Published online: 14 August 2020

(c) The Author(s) 2020

\begin{abstract}
Remember how Kim (Philos Perspect 3:77-108, 1989, in: Heil and Mele (eds) Mental causation, Clarendon Press, Oxford, 1993b) used to argue against non-reductive physicalism to the effect that it cannot accommodate the causal efficacy of the mental? The argument was that if physicalists accept the causal closure of the physical, they are faced with an exclusion problem. In the original version of the argument, the dependence holding between the mental and the physical was cashed out in terms of supervenience. Due to the work or Fine (Philos Perspect 8:1-16, 1994) and others, we have since come to realize that modal notions are not well-suited to perform the work of properly characterizing dependence. As a consequence of this, an increasingly larger community of contemporary metaphysicians prefer to spell out mental-physical dependence in terms of a non-causal and non-reductive notion called grounding, which is intended to target a particular sort of metaphysical relation that takes us from ontologically less fundamental features of the world to that which is more fundamental. In this paper I join forces with those who think that this shift in focus is on the right track. More specifically, I will argue that the grounding physicalist can solve the exclusion problem in a way that is preferable to the supervenience-based nonreductive physicalist solution, as well as in a way that is compatible with the externalist picture of the mental.
\end{abstract}

Keywords Metaphysical grounding · Non-reductive physicalism · Causal exclusion · Overdetermination · Externalism

Robin Stenwall

robin.stenwall@fil.lu.se

1 Department of Philosophy, Lund University, Box 192, 22100 Lund, Sweden

2 Department of Philosophy, Linguistics and Theory of Science, University of Gothenburg, Box 200, 40530 Gothenburg, Sweden 


\section{Introduction}

Remember how Kim $(1989,1993 b)$ used to argue against non-reductive physicalism to the effect that it cannot accommodate the causal efficacy of mental properties? The argument was that if physicalists accept the causal closure of the physical (i.e. the idea that every physical effect has a physical cause), they are faced with an exclusion problem; that is to say, they are committed to a systematic and objectionable form of causal overdetermination. In the original version of the argument, the dependence holding between the mental and the physical was cashed out in terms of supervenience. Due to the work of Fine (1994) and others, we have since then come to realize that modal notions are not well-suited to perform the work of properly characterizing dependence. Notions like necessitation and supervenience are, among other things, governed by the wrong structural principles and too coarse-grained to capture the intended notion. As a consequence of this, contemporary metaphysicians have largely given up on attempts at understanding dependence in terms of modal covariation. Instead they prefer to spell it out in terms of a non-causal and non-reductive notion called grounding, which is intended to target a particular sort of metaphysical relation (to be elucidated below) that takes us from ontologically less fundamental features of the world to that which is more fundamental.

In this paper I join forces with those who think that this shift in focus, from a characterization of the mental-physical bond in terms of supervenience to a characterization in terms of grounding, is on the right track. More specifically, I will argue that the exclusion problem can be solved if we allow for grounding physicalism, i.e. the claim that all mental facts are grounded by physical facts. In the next section, I will give a brief introduction to the notion of grounding and then go on to generate the exclusion worry. In Sect. 3, I will develop an account of causation in terms of facts and fundamental grounds. In Sect. 4, I address and provide a solution to the exclusion problem in light of the account developed in the previous section. Section 5 is dedicated to a discussion of two potential problems with the grounding physicalist view. Section 6 summarizes the main points of the paper.

\section{Grounding physicalism and the exclusion problem}

There is an ever-growing literature on the notion of grounding, and due to lack of space, I will not go into some of its more advanced treatments. However, a few preliminary remarks are in order. I will assume, without further argument, that grounding expressions ultimately behave like predicates that introduce a certain hyperintensional and non-monotonic priority relation that holds exclusively among facts. Facts are here taken to be what true propositions state (cf. Mellor 1995, pp. 8-9). Thus, the proposition $\langle\mathrm{P}\rangle$ is true if and only if $[\mathrm{P}]$ obtains, where ' $[\mathrm{P}]$ ' denotes the fact that $\mathrm{P}$. Not all facts in this liberal, uncontentious sense of 'fact' should be identified with sui generis types of entities in which objects instantiates properties or stand in relations (i.e. states 
of affairs). ${ }^{1}$ I will also assume that grounding is well-founded and that it induces a strict partial ordering on the set of entities in its range, i.e. it exhibits asymmetry, irreflexivity and transitivity. ${ }^{2}$ Grounding chains terminate in fundamental facts, where a fact is fundamental if it is ungrounded. Moreover, by 'grounding' I will always mean full grounding, where, intuitively, nothing needs to be added to a full ground to get a fully satisfactory explanation of what it grounds. ${ }^{3}$

With these preparations in place, let grounding physicalism state the following:

Grounding Physicalism. All mental facts are grounded by (non-mental) physical facts.

To spell this out in more detail, let us say that some collection of one or more facts $\Delta_{\mathrm{p}}$ constitutes a physical ground for some mental fact $[\mathrm{P}]_{\mathrm{m}}$ just in case: (i) $\Delta_{\mathrm{p}}$ consists solely of non-mental facts ${ }^{4}$; (ii) no fact among $\Delta_{\mathrm{p}}$ is grounded by mental facts; and (iii) $\Delta_{\mathrm{p}}$ grounds $[\mathrm{P}]_{\mathrm{m}}$. We can then take grounding physicalism to be the thesis that all mental facts have physical grounds.

Since grounding is a strict partial ordering, Grounding Physicalism entails:

Non-Reduction. All mental facts are distinct from their physical grounds. ${ }^{5}$

Grounding physicalism is thus an extension of non-reductive physicalism in that it takes the mental to be less fundamental than and dependent on the physical, while simultaneously denying that the mental reduces to the physical. What distinguishes grounding physicalism from standard formulations of non-reductive physicalism is that the latter usually appeal to a purely technical notion like supervenience to explicate the relation between the mental and the physical (Kim 2005, pp. 33-34), whereas the former explicates the mental-physical bond in terms of the more substantial relation

\footnotetext{
1 Among other things, there is an abundance of liberal facts of the form [x exists]. However, most would baulk at the idea that there is a corresponding entity in which some object $\mathrm{x}$ instantiates the property of existing. Similarly, there are liberal facts of the form $[\mathrm{x}$ is not $\mathrm{F}]$. But again, there is no corresponding entity in which $\mathrm{x}$ instantiates the property of not being $F$ - this, since there are no negative properties (cf. Mellor 1995, pp. 196-99). We will have reason to discuss the connection between liberal facts and a privileged subset of such facts (i.e. states of affairs) in Sect. 3 .

2 This claim is thought by some to be subject to counterexamples. Thus, Thompson (2016) argues that there are genuine instances of grounding that violate asymmetry; Fine (2010) and Krämer (2013) discuss cases that seem to go against irreflexivity; and Schaffer (2012) provides counterexamples to transitivity. In fact, there are even those who, like Rodriguez-Pereyra (2015), think that grounding exhibits none of the features that make up a strict ordering. It remains controversial, however, whether the counterexamples succeed (Raven 2013 and Litland 2013), and I notice that many grounding theorists accept (plausibly for theoretical reasons) that grounding induces a strict partial ordering by identifying fundamental facts with minimal elements of the ordering. I take the advantages of this view, inasmuch as it establishes a hierarchical structure that takes us from the less fundamental to the increasingly fundamental, to outweigh any problems raised by counterexamples.

I would like to thank an anonymous referee for drawing my attention to this problem.

3 In addition to this, grounds can also be partial, where a partial ground contributes to the explanation of what it grounds.

4 I take non-mental facts to include physical facts and facts that are neither mental nor physical (e.g. indexical facts).

5 Non-reductive physicalism is the view that mental facts do not reduce to physical facts. For simplicity, I will assume that non-identity entails non-reducibility and thus that grounding physicalism is properly categorized as a form of non-reductive physicalism. I would like to thank an anonymous referee for making me aware of the importance of grounding physicalists to distance themselves from reductive physicalists.
} 
of grounding. What I mean by calling supervenience a 'purely technical notion' is that it merely tracks certain patterns of modal covariation without accounting for why these patterns hold (Kim 1998, pp. 9-15; Blackburn 1984, p. 186; McGinn 1993, p. 57). Grounding, by contrast, is an explanatory notion (Dasgupta 2014, p. 558) that picks out a relation that exhibits both directionality and a more articulated structure (Schaffer 2017, p. 10). Although I will not discuss the matter in detail here, the hope among grounding physicalists is that the global supervenience of the mental on the physical is to be explained by the nature of ground.

To have a better interaction between grounding and causation, I will take causation to hold exclusively between facts. More specifically, I will frame the discussion using D. H. Mellor's theory of causation (1995) according to which singular causation is a matter of a fact raising the chance of another fact. The proposed solution to the exclusion problem is not committed to Mellor's view in particular. However, Mellor's view is a well-worked-out theory of causation that make use of ground (in the form of truthmakers) and facts in a way that makes these notions easy to integrate into the framework. In the next section, I will discuss the details of Mellor's theory. For now, it suffices to see that our physicalist is susceptible to an exclusion problem in terms of facts that is analogous to the ones in terms of events that arises for more traditional versions of non-reductive physicalism. To see this, let $[\mathrm{C}]_{\mathrm{p}}$ be a physical ground for some mental fact $[\mathrm{C}]_{\mathrm{m}}$ in accordance with (i)-(iii). Suppose furthermore that $[\mathrm{C}]_{\mathrm{m}}$ is a sufficient cause of a physical fact $[\mathrm{E}]_{\mathrm{p}}$ at a successive time. Since $[\mathrm{C}]_{\mathrm{m}}$ is grounded by $[C]_{p}$, it seems that the latter fact also suffices for the same physical effect. But then it would appear that $[\mathrm{E}]_{\mathrm{p}}$ is overdetermined by $[\mathrm{C}]_{\mathrm{m}}$ and $[\mathrm{C}]_{\mathrm{p}}$. Moreover, since the facts involved are arbitrary, the reasoning generalizes to the effect that mentalphysical overdetermination is ubiquitous. This is worrying. Competing causes for the same effect exclude one another in that one of them leaves no causal work to be done by the other. And since it is not possible to view $[\mathrm{C}]_{\mathrm{p}}$ and $[\mathrm{C}]_{\mathrm{m}}$ as forming a single jointly sufficient cause where each is individually necessary but insufficient for $[\mathrm{E}]_{\mathrm{p}}$, it looks like we are forced to choose between the alleged causes. ${ }^{6}$

There are several ways our non-reductive physicalist could avoid the exclusion problem. Denying either of the following could do this:

Mental Causation. Some mental facts cause physical facts.

Causal Closure. Every physical fact that has a cause has a sufficient physical cause (or has its probability fixed by purely physical antecedents). ${ }^{7}$

However, neither strategy is particularly attractive. Denying Mental Causation requires us to modify our view about the mind enormously, whereas denying Causal Closure

\footnotetext{
${ }^{6}$ Of course, we would not really be forced to choose between $[\mathrm{C}]_{\mathrm{m}}$ and $[\mathrm{C}]_{\mathrm{p}}$ if they are identical. But they're not. Non-Reduction renders each mental fact distinct from its physical ground. Nor would we be any better off arguing that $[\mathrm{C}]_{\mathrm{p}}$ causes $[\mathrm{C}]_{\mathrm{m}}$, which in turn causes $[\mathrm{E}]_{\mathrm{p}}$. To be sure, both $[\mathrm{C}]_{\mathrm{m}}$ and $[\mathrm{C}]_{\mathrm{p}}$ would then be causes of $[E]_{p}$ as a result of causal transitivity, rather than overdetermination. But to think that $[\mathrm{C}]_{\mathrm{p}}$ causes $[\mathrm{C}]_{\mathrm{m}}$ in the same way as, say, the striking causes the vase to break is downright absurd. It is absurd, since $[C]_{p}$ will be simultaneous with $[C]_{m}$, rather than, as in the case of the vase being struck and breaking, the cause preceding the effect. It is therefore difficult to see $[\mathrm{C}]_{\mathrm{p}}$ and $[\mathrm{C}]_{\mathrm{m}}$ as distinct causal links leading up to $[\mathrm{E}]_{\mathrm{p}}$.

${ }^{7}$ For ease of exposition, I will mainly speak of sufficient physical causes but within a probabilistic framework.
} 
allows for the physical world to contain gaps that must be filled in by non-physical facts to fully explain the physical facts. I take it, however, that no physicalist is prepared to take this route. ${ }^{8}$ This leaves the non-reductive physicalist to deny either:

Overdetermination. Any fact with two (or more) sufficient causes is overdetermined, or

Exclusion. Physical effects of mental facts are not systematically overdetermined.

To reject Exclusion is to allow for ubiquitous mental-physical overdetermination in which every time you act there are two distinct causes converging on the same effec$\mathrm{t}$ - something which is thought to be a violation of the Occamian idea that one ought not multiply causes beyond necessity (cf. Kim 1989, p. 98). However, this need not be as bad as it sounds. For it could be argued that not all forms of overdetermination are created equal - that there is a distinction to be drawn between harmful and permissible overdetermination, where mental-physical overdetermination is of the latter kind. Systematic overdetermination involving several independent causes, each of which in the absence of the other suffices to bring about the same effect, would indeed be an inexplicable coincidence and a crude violation of the Occamian idea. But nothing like this seems to be going on in the way the physical effects of mental causes are overdetermined. The overdetermination involved when the fact that Bill is in pain and the fact that Bill's c-fibers are firing cause the fact that Bill winces is nothing like the overdetermination involved when the fact that the window shatters is caused by the simultaneous rock-throwing actions of Suzy and Bill. The way in which the physical fact that Bill winces is overdetermined seems to be permissible in more or less the same way that we judge the fact that the window shatters to be permissibly overdetermined by the throwing of the rock and the throwing of its parts (cf. Sider 2003, pp. 722-23).

Another way out of the exclusion problem is to deny Overdetermination by arguing that some effects have two (or more) sufficient causes without thereby being overdetermined. For the sake of the argument, I will henceforth accept Overdetermination but deny Exclusion. But not only that. I will also deny that any fact with two (or more) sufficient causes is to be considered harmfully overdetermined. This is exactly what I need in order to show that although mental-physical causal overdetermination is ubiquitous, this need not worry us. From the perspective of grounding physicalism, this strategy looks promising. For although mental facts, on this view, are not identical to the facts they depend on (i.e. their physical ground), they are nonetheless said to be nothing 'over and above' them in that there is no further condition that the prior physical facts need to fulfil for the posterior mental facts to obtain. ${ }^{9}$ Prima facie, this allows the grounding physicalist to argue that the kind of overdetermination involved in mental-physical causation is nothing like the standard cases of overde-

\footnotetext{
8 More specifically, as physicalists we think that a final physics will provide a complete explanation of the facts (or their chances). While physics may leave some explanatory gaps (e.g. in the explanation of inherently indeterministic phenomena), it leaves no gaps of a kind that can be occupied by non-physical causes.

9 The only grounding theorist I've found that explicitly denies this is Audi (2012).
} 
termination - the mental facts being nothing in addition to the underlying physical facts.

The task of the rest of the paper is to spell out in more detail what this failure of mental-physical overdetermination amounts to. More specifically, I will provide an explanation of why grounding physicalism is able to defuse the threat of overdetermination by offering a necessary condition on harmful overdetermination. To go about this task, I will need an account of causation in terms of facts and fundamental grounds. Since I've presented the details of such a theory elsewhere (Stenwall 2010, 2017) and the aim of the discussion is not to say what causation $i s$, but to provide a solution to the exclusion problem, the presentation of my preferred view of causation will be brief.

\section{Grounds for causal facts}

Following Mellor (1995, p. 11), I take the canonical form of causal claims to be:

(CT) E because C,

where 'because' is a non-truth-functional connective between two propositions, the first of which states the effect and the second of which states the cause. ${ }^{10}$ Since neither $\langle\mathrm{E}\rangle$ nor $\langle\mathrm{C}\rangle$ can be false if (CT) is true, (CT) is equivalent with:

(CF) [C] causes [E] (Mellor 1995, p. 11),

where $[\mathrm{C}]$ and $[\mathrm{E}]$ are facts in the liberal sense of 'fact' given above.

But this tells us nothing about what in the world, if anything, makes causal instances of (CT) true and, hence, instances of (CF) state causal facts. To settle this question, we need to be told what their fundamental grounds are. The reason for this is two-fold. First of all, facts in the liberal sense above are seldom fundamental in that if a certain proposition $\langle\mathrm{P}\rangle$ states a fact $[\mathrm{P}]$, then it usually does so in virtue of something else-its ground (cf. Rodriguez-Pereyra 2005, p. 21; Schaffer 2008, p. 308). Secondly, if such facts are not fundamental, then they must be grounded in that which $i s$ fundamental (cf. Schaffer 2008, p. 308). ${ }^{11}$ Let us thus say that some collection of facts $\Delta$ constitutes

\footnotetext{
10 'because' is not an exclusively causal locution, being used, among other things, to give proofs and non-causal explanations. There are thus many non-causal instances of (CT) that I must exclude, and I will do so by restricting (CT) to instances that have exclusively causal equivalents.

11 Let $\Delta_{\mathrm{p}}$ be a collection of fundamental physical facts and $[\mathrm{P}]_{\mathrm{m}}$ a mental fact, such that $\Delta_{\mathrm{p}}$ grounds $[\mathrm{P}]_{\mathrm{m}}$. It is then a fact that $\Delta_{\mathrm{p}}$ grounds $[\mathrm{P}]_{\mathrm{m}} \cdot\left[\Delta_{\mathrm{p}}\right.$ grounds $\left.[\mathrm{P}]_{\mathrm{m}}\right]$ must be either derivative (i.e. grounded) or fundamental (i.e. ungrounded). In view of Ted Siders Purity Principle (2011: 106-9) fundamental facts are pure in the sense that they only involve facts that are specified by fundamental notions. But if so, it is hard to see how $\left[\Delta_{\mathrm{p}}\right.$ grounds $\left.[\mathrm{P}]_{\mathrm{m}}\right]$ could be fundamental as it is partly constituted by a mental fact. What is more, $\left[\Delta_{\mathrm{p}}\right.$ grounds $\left.[\mathrm{P}]_{\mathrm{m}}\right]$ isn't a physical fact and so, it would violate against the claim that all fundamental facts are physical. On the other hand, if the grounding fact is derivative, we need to be told what its fundamental ground(s) are and it is not clear how the story would go. For if $\left[\Delta_{\mathrm{p}}\right.$ grounds $\left.[\mathrm{P}]_{\mathrm{m}}\right]$ requires some collection of fundamental facts $\Gamma$ that grounds it, we need to be told what grounds $\left[\Gamma\right.$ grounds $\left[\Delta_{\mathrm{p}}\right.$ grounds $\left.\left.[\mathrm{P}]_{\mathrm{m}}\right]\right]$. But now it looks like we are susceptible to an infinite regress. For we also need to be told what it is that grounds the corresponding grounding fact about what grounds $\left[\Gamma\right.$ grounds $\left[\Delta_{p}\right.$ grounds $\left.\left.[\mathrm{P}]_{\mathrm{m}}\right]\right]$ and so on.

Due to a lack of space I will set aside the problem of iterated ground, i.e. the problem of what, if anything, grounds facts about what grounds what and assume that there is a solution to this problem to be had. Suffices
} 
a fundamental ground for some fact $[\mathrm{P}]$ just in case: $\Delta$ consists solely of ungrounded facts; and $\Delta$ grounds [P]. For grounding physicalists that take grounding to be wellfounded, all mental facts are fundamentally grounded in (non-mental) physical facts and so, if $[\mathrm{P}]_{\mathrm{m}}$ is a mental fact such that $\Gamma$ is $[\mathrm{P}]_{\mathrm{m}}$ 's fundamental ground, then each fact in $\Gamma$ is non-mental. Following Mellor (1995, pp. 183-84), I take these fundamental facts (Mellor calls them facta) to be things' having properties, where by 'properties' I mean perfectly natural (i.e. sparse) properties specified by terms that carve nature at the joints. These are the ontologically privileged facts, and I will use italicized lowercase letters to denote such facts. This yields the relevant sense in which the grounded mental facts are nothing 'over and above' the fundamental physical facts that ground them-they are ultimately not an addition to them (cf. Sider 2011, pp. 105-141; 198-199). ${ }^{12}$

To this one might object that the notion of nothing-over-and-aboveness remains too vague to be used in a fruitful way. That would be a mistake. There are many central cases on which most grounding theorists agree: for example, I take it that most would agree that $[a$ is a rectangle] is nothing over and above [ $a$ is equiangular and quadrilateral] and that this is due to the fact that there is no further condition that the grounding fact needs to fulfil for the grounded fact to obtain. To be sure, our intuitions concerning when some fact can be said to be nothing over and above some other fact vary. But the same holds true of our intuitions concerning when some fact can be said to be the cause of some other fact or when someone can be said to know something; yet, this does not invalidate notions like causation and knowledge in philosophical theorizing. In the following I take the notion of nothing-over-andaboveness to be legitimate. Moreover, I will put the notion to work by taking it to drastically reduce our ontological commitments. By admitting $[\mathrm{P}]$ there is no need for our ontology to recognize anything other than [P]'s fundamental ground. Whatever is ontologically derived from [P]'s fundamental ground, like [P] itself, does not add to the

\footnotetext{
Footnote 11 continued

it for present purposes to mention that there are a number of ways for the grounding physicalist to deal with the problem. One could simply accept that facts about what grounds mental facts are fundamental and deny both the Purity Principle and the claim that all fundamental facts are physical—which, notice, is fully compatible with the claim that all mental facts are fundamentally grounded in the physical (i.e. given that facts about what grounds mental facts are not themselves mental facts). Another way to go about the problem is to accept that facts about what grounds mental facts are derivative and then provide grounds for grounding facts that do not yield an infinitely descending chain of ground. There are a number of such solutions on the table. One is Litland's (2017) Zero-Grounding Account according to which facts about what grounds what are zero-grounded, where a fact is zero-grounded if and only if it is grounded, but in the empty collection of facts. Another view defended by Bennett (2011) and deRosset (2013) is the so-called Straightforward Account according to which, whenever $\Delta$ grounds [P], $\Delta$ also grounds [ $\Delta$ grounds [Q]]. Both of these solutions stop the regress from progressing (Litland 2017 and Bennett 2011: 33-36). For criticism of invoking zero-ground to solve the problem of iterated ground, see Bohn (2018) and for criticism against the Straightforward Account, see Litland (2017). A third solution is the Grounding Essentialist view according to which whenever $\Delta$ grounds [P], [ $\Delta$ grounds [Q]] is (at least partially) grounded in the essential connection between (some or all constituents) of $\Delta$ and [P] (Wallner forthcoming). See also Kovacs (forthcoming) for an interesting discussion about the problem of iterated ground.

12 This is not to say that if some fact [P] is nothing 'over and above' some collection of physical facts $\Delta_{\mathrm{p}}$, that each fact in $\Delta_{\mathrm{p}}$ is fundamental. It is still useful to recognize a mental cause $[\mathrm{C}]_{\mathrm{m}}$ as nothing 'over and above' some physical cause $[\mathrm{C}]_{\mathrm{p}}$ that grounds $[\mathrm{C}]_{\mathrm{m}}$ even when $[\mathrm{C}]_{\mathrm{p}}$ itself is grounded. After all, given that $[\mathrm{C}]_{\mathrm{m}}$ is grounded by $[\mathrm{C}]_{\mathrm{p}}$, there is no further condition that $[\mathrm{C}]_{\mathrm{p}}$ needs to fulfil for $[\mathrm{C}]_{\mathrm{m}}$ to obtain.
} 
ontological cost and should therefore not be included into the ontology in addition to what is required at the fundamental level to derive [P] (Heil 2003, 2012, pp. 163-166; Cameron 2008, Cameron 2010). For reason of parsimony, I thus take our ontological commitments to be restricted to the fundamental.

With the relevant notion of fundamentality and ontological commitment in place, let us consider what makes causal instances of (CF) state facts of the form [[C] causes [E]]. Notice that since $(\mathrm{CT})$ is not a complete truth function of $\langle\mathrm{E}\rangle$ and $\langle\mathrm{C}\rangle$, the truth of the latter two propositions does not entail the truth of the former. This is why, in order for instances of $(\mathrm{CF})$ to be factual, they will require a fundamental ground with (at least) three components: one for the stated cause [C], another one for the stated effect $[\mathrm{E}]$ and a third one to make $[\mathrm{C}]$ the cause of $[\mathrm{E}] .{ }^{13}$ According to Mellor, the third component must be such that it makes the stated cause raise the chance of the stated effect, which he writes as ' $c h(E)$ '. This chance (which states an objective probability) is a property of the cause [C] and the relevant circumstances in which (CT) is true. By saying that the cause [C] raises $\operatorname{ch}(\mathrm{E})$ in the relevant circumstances is meant that the chance of the effect $[\mathrm{E}]$ given the cause is higher than it would be in those circumstances if the cause didn't obtain, i.e. $\operatorname{ch}_{\mathrm{C}}(\mathrm{E})>\operatorname{ch}_{\sim \mathrm{C}}(\mathrm{E})$ (Mellor 1995, p. 67). By employing Lewis-style conditionals (1973), we can say that these are the chances $p$ and $p^{\prime}$ such that in the relevant circumstances:

(1) $\mathrm{C} \Rightarrow \operatorname{ch}(\mathrm{E})=p$, and

(2) $\sim \mathrm{C} \Rightarrow \operatorname{ch}(\mathrm{E})=p^{\prime}$.

What makes (1) and (2) true are then those fundamental facts that join with the laws of nature to make the stated cause raise the chance of the stated effect. To illustrate, suppose the true causal instance of (CT) we are considering is:

(3) Bill winces because he is in pain.

Let $\mathrm{S}$ be the relevant circumstances in which (3) is true. Since Bill cannot wince because he is in pain if he does not wince or is not in pain, we need to say what makes the corresponding cause and effect state facts. Thus, let [wince $]_{\mathrm{p}}$ and $[\text { pain }]_{\mathrm{p}}$ be those fundamental physical facts that make it a fact that Bill winces and a fact that Bill is in pain respectively. What makes (3) state a causal fact is then a collection of fundamental facts consisting of $[\text { wince }]_{\mathrm{p}}$, [pain $]_{\mathrm{p}}$ together with, plausibly, a large number of facts involving the physical state of Bill's central nervous system. For assuming that the causation involved is deterministic, these facts join with the laws of nature in $\mathrm{S}$ to give the chance that Bill winces a value of 1 if he is in pain and a value of 0 if he is not in pain, ${ }^{14}$ i.e. these fundamental facts join with the laws of nature in the relevant circumstances to make it the case that:

\footnotetext{
13 When either $\langle\mathrm{C}\rangle$ or $\langle\mathrm{E}\rangle$ states a fundamental fact, either of the corresponding facts will be ungrounded. But this is not a problem. For notice that what we are trying to find grounds for is the causal fact stated by $(\mathrm{CF})$ and there is no violation of irreflexivity in taking $[[\mathrm{C}]$ causes [E]], when either the cause or the effect is fundamental, to be partially grounded in either of the fundamental facts themselves (i.e. $[c]$ or $[e]$ ).

14 I take it that the laws that join with the fundamental facts are themselves fundamental and that grounding physicalists cannot allow for psychophysical laws that are fundamental.
} 
(4) Bill is in pain $\Rightarrow \operatorname{ch}$ (Bill winces) $=1$, and

(5) Bill is not in pain $\Rightarrow c h$ (Bill winces) $=0$.

As in this case, so in general: whenever causal instances of (CT) are true and hence, instances of $(\mathrm{CF})$ state facts, there are some corresponding fundamental facts that in the relevant circumstances join with the laws of nature to make (1) and (2) true for some $p$ and $p^{\prime}$ such that $p>p^{\prime} .^{15}$

\section{A grounding physicalist solution to the exclusion problem}

We are now in a position to address the exclusion problem. Again, suppose that (3) is true in $\mathrm{S}$ and let $[\mathrm{PAIN}]_{\mathrm{m}}$ be the mental fact that Bill is in pain and [WINCE $]_{\mathrm{p}}$ the physical fact that Bill winces. Since Bill must wince and be in pain for (3) to be true, we are committed to:

(6) $[\mathrm{PAIN}]_{\mathrm{m}}$ causes $[\mathrm{WINCE}]_{\mathrm{p}}$.

Now, suppose in accordance with Grounding Physicalism that $[\mathrm{PAIN}]_{\mathrm{m}}$ is fully grounded by $[\mathrm{C}-\mathrm{FIBER}]_{\mathrm{p}}$, where the latter is the physical fact that Bill's c-fibers are firing. But then, if (6) is true in the relevant circumstances $S$, so is:

(7) $[\text { C-FIBER }]_{p}$ causes $[\text { WINCE }]_{p}$.

There is no further condition that the prior physical fact needs to fulfil for the corresponding mental fact to obtain in S. So if $[\mathrm{PAIN}]_{\mathrm{m}}$ is causally sufficient for $[W I N C E]_{p}$ in $S$ to the extent specified by (4), then the same holds true of [C-FIBER $]_{p}$. Similarly, had Bill's c-fibers not fired under those circumstances, the chance that Bill winces would be zero. ${ }^{16}$ In other words, the following conditionals:

15 Actually, this is not quite right. Suppose the conditionals we are considering are:

$\mathrm{F} a \Rightarrow \operatorname{ch}(\mathrm{A}=\mathrm{F} / \mathrm{M})=1$ and

$\& \sim \mathrm{F} a \Rightarrow \operatorname{ch}(\mathrm{A}=\mathrm{F} / \mathrm{M})=0$,

where ' $\mathrm{F}$ ' and ' $\mathrm{M}$ ' range over net forces and values of mass respectively, and $\mathrm{A}$ is $a$ 's acceleration. If $\mathrm{F}$ alters $a$ 's mass M (e.g. by knocking spots off it), it will not make $a$ accelerate at F/M, and so, will not make the chance of that acceleration 1 (Mellor 1995, p. 173). The chance of $a$ accelerating at F/M will only be guaranteed if applying $\mathrm{F}$ to $a$ does not alter its mass. In effect, the chance-raising conditionals made true by $a$ 's having $\mathrm{M}$ are not the above, but the following:

$\mathrm{M} a \& \mathrm{~F} a \Rightarrow \operatorname{ch}(\mathrm{A}=\mathrm{F} / \mathrm{M})=1$ and

$\mathrm{M} a \& \sim \mathrm{F} a \Rightarrow \operatorname{ch}(\mathrm{A}=\mathrm{F} / \mathrm{M})=0$

(Mellor 1995, p. 178). This difference, however, does not affect the core of the argument made here.

16 This might seem problematic given a functionalist interpretation of 'is in pain', for it could then be argued that the closest possible worlds where Bill's c-fibers are not firing are worlds where $[\mathrm{PAIN}]_{\mathrm{m}}$ is grounded in something other than $[C-F I B E R]_{p}$, in which case we would not be guaranteed that had Bill's c-fibers not fired, then $\operatorname{ch}$ (Bill winces) $=0$.

But this way of evaluating counterfactuals is highly problematic. We are imagining a case where the closest possible worlds in which the antecedent is true are worlds in which the physical fact is replaced, rather than merely negated. This is akin to the way some philosophers have treated counterfactuals where the antecedent denies the occurrence of a particular event (see e.g. Lepore and Loewer 1987, p. 639; Mills 1996, p. 109; Pietroski 1994, pp. 358-59). But as noted by Karen Bennett (2003, pp. 478-82), this makes the business of evaluating counterfactuals far too easy and is, at least, as problematic as backtracking evaluations. The proper way to evaluate counterfactuals with negative antecedents is to imagine the corresponding 'positive' fact as not obtaining, without making assumptions about how this would have an impact on the past, or what else might obtain in its place (Bennett 2003, p. 482; Lewis 2000, p. 190). 
Bill's c-fibers are firing $\Rightarrow c h$ (Bill winces $)=1$, and

Bill's c-fibers are not firing $\Rightarrow c h$ (Bill winces $)=0$,

are both true in $\mathrm{S}$. More generally, in the relevant circumstances:

Dual Causation. If $[\mathrm{C}]_{\mathrm{m}}$ is some mental fact and $[\mathrm{E}]_{\mathrm{p}}$ some physical fact such that $[\mathrm{E}]_{\mathrm{p}}$ is an effect of $[\mathrm{C}]_{\mathrm{m}}$, then there is some physical fact $[\mathrm{C}]_{\mathrm{p}}$ that grounds $[\mathrm{C}]_{\mathrm{m}}$ and causes $[\mathrm{E}]_{\mathrm{p}} \cdot{ }^{17,18}$

Grounding Physicalism together with the innocuous nature of grounded facts thus yield a proliferation of dual causes that converge on the same physical effect, thereby rendering Exclusion false by virtue of Overdetermination. So why is this not one cause too many? Why is $[\mathrm{E}]_{\mathrm{p}}$ not harmfully overdetermined by $[\mathrm{C}]_{\mathrm{m}}$ and $[\mathrm{C}]_{\mathrm{p}}$ ?

To answer this, we need a way to distinguish, among effects with two or more apparent causes, those that are harmfully overdetermined from those that are not. Suppose that $[\mathrm{C}]$ and $\left[\mathrm{C}^{\prime}\right]$ are both alleged causes of $[\mathrm{E}]$. The traditional test for overdetermination states that for $[\mathrm{C}]$ and $\left[\mathrm{C}^{\prime}\right]$ to harmfully overdetermine $[\mathrm{E}]$, the alleged causes must each cause [E] without the other (cf. Mellor 1995, pp. 101-03; Mills 1996, p. 107; Bennett 2003, pp. 476-80). In the present chance-raising context, this means that $[\mathrm{E}]$ is harmfully overdetermined by $[\mathrm{C}]$ and $\left[\mathrm{C}^{\prime}\right]$ only if:

$$
\mathrm{C} \Rightarrow \operatorname{ch}(\mathrm{E})=p
$$

is non-vacuously true in the absence of $\left[\mathrm{C}^{\prime}\right]$, and

$$
\mathrm{C}^{\prime} \Rightarrow \operatorname{ch}(\mathrm{E})=p^{\prime}
$$

is non-vacuously true in the absence of [C] for some $p$ and $p^{\prime}$ such that $p>c h_{\sim \mathrm{C}}(\mathrm{E})$ and $p^{\prime}>c h_{\sim C^{\prime}}(\mathrm{E})$. Conversely, if either conditional is false or vacuous, then $[\mathrm{E}]$ is not harmfully overdetermined by $[\mathrm{C}]$ and $\left[\mathrm{C}^{\prime}\right]$. The test is intended to be entirely general. Take any case you like. If both conditionals are false, i.e. if neither $[\mathrm{C}]$ nor $\left[\mathrm{C}^{\prime}\right]$ raises the chance of $[\mathrm{E}]$ without the other, then $[\mathrm{E}]$ is not overdetermined, but is jointly caused by $[\mathrm{C}]$ and $\left[\mathrm{C}^{\prime}\right]$. On the other hand, if only one of the conditionals is false, i.e. if only one of the alleged causes raises the chance of the effect in the absence of the other, then at most one of either $[\mathrm{C}]$ or $\left[\mathrm{C}^{\prime}\right]$ causes $[\mathrm{E}]$ on its own. And if both conditionals are vacuous, then $[\mathrm{E}]$ is not harmfully overdetermined by $[\mathrm{C}]$ and $\left[\mathrm{C}^{\prime}\right]$-which, of course, it can't be if, say, $[\mathrm{C}]$ is identical to $\left[\mathrm{C}^{\prime}\right]$.

In standard cases of overdetermination-like those involving broken windows and firing squads - the conditionals are non-vacuously true in that each of the alleged causes states a possibility that raises the chance of the effect in the absence of the other cause. This differs radically from the picture put forth by the grounding physicalist of the kind of 'overdetermination' involved when the fact that Bill winces is caused both by the fact that his c-fibers are firing and the fact that he is in pain. In the mental-physical case the physical cause is contingent on the mental cause in a way that renders:

\footnotetext{
17 Although I will primarily be concerned with cases where both $[\mathrm{C}]_{\mathrm{p}}$ and $[\mathrm{E}]_{\mathrm{p}}$ are themselves grounded, I will allow for cases where either the physical cause or the physical effect (or both) are fundamental.

18 Thomas Kroedel and Moritz Schulz (2016, p. 1915) argue for a similar principle they call Double Causation on the basis of a causal inheritance principle and the factivity of grounding.
} 


\section{(8) Bill's c-fibers are firing $\Rightarrow \operatorname{ch}($ Bill winces $)=p$}

either false or vacuously true for some $p$ such that $p>c h$ (Bill winces) would have been had Bill's c-fibers not fired. Whether (8) is vacuous or false in circumstances where Bill is not in pain depends on whether or not mental facts are necessitated by their physical grounds. Needless to say, if $[\mathrm{C}-\mathrm{FIBER}]_{\mathrm{p}}$ necessitates $[\mathrm{PAIN}]_{\mathrm{m}}$ in that it is impossible for $[\mathrm{C}-\mathrm{FIBER}]_{\mathrm{p}}$ to obtain without $[\mathrm{PAIN}]_{\mathrm{m}}$, then $(8)$ is vacuous in circumstances where Bill is not in pain. If, on the other hand, the antecedent is possible in such circumstances, then the conditional is false. For had Bill's c-fibers fired in circumstances where he is not in pain, the chance of him wincing would be zero. This is not to say that $[\mathrm{C}-\mathrm{FIBER}]_{\mathrm{p}}$ needs $[\mathrm{PAIN}]_{\mathrm{m}}$ to cause $[\mathrm{WINCE}]_{\mathrm{p}}$. Rather, the claim is that in order for [C-FIBER $]_{p}$ to raise the chance of the fact that Bill winces, the physical circumstances that necessitate $[\mathrm{PAIN}]_{\mathrm{m}}$ must obtain (Bennett 2003, pp. 488-89). This means that if $[\mathrm{C}-\mathrm{FIBER}]_{\mathrm{p}}$ had obtained without $[\mathrm{PAIN}]_{\mathrm{m}}$, those circumstances would not obtain, in which case $[\mathrm{C}-\mathrm{FIBER}]_{\mathrm{p}}$ would not cause $[\mathrm{WINCE}]_{\mathrm{p}}$. The grounding physicalist can thus explain why mental-physical causation fails to pass the traditional test for harmful overdetermination regardless of whether or not there can be mentalphysical grounding without necessitation. We will return to the role that circumstances play later on when discussing a potential externalist threat.

Still, as a general necessary condition on overdetermination, the traditional test is not entirely satisfactory. According to it, reference to a sufficiently tight connection between the mental and the physical is enough to defuse the threat of mental-physical overdetermination. But what kind of tight connection? The standard non-reductivist answer is that the 'tightness' is to be spelt out in modal terms like supervenience or metaphysical necessitation. And there is indeed something to be said for the idea that the presence of such connections helps to reduce our worry that the overdetermination involved is of the harmful kind. However, this can't be the whole story. Purely modal connections like supervenience or metaphysical necessitation tell us nothing about the nature of mental-physical dependence, other than that it entails various patterns of modal covariation. Among other things, they do not exhibit directionality in that if some fact $[\mathrm{P}]$ is supervenient on or necessitated by some collection of facts $\Delta$, then the facts in $\Delta$ need not be more fundamental than [P]. It is fully compatible with either modal connection that $\Delta$ is equally fundamental to $[\mathrm{P}]$ or less fundamental than [P]. I take it that any non-reductive physicalist worthy of the epithet takes the mental to be less fundamental than the physical and the directionality to be built into the dependence at hand. Neither supervenience nor metaphysical necessitation is up to the task.

More importantly, reference to a tight connection to avoid causal overdetermination works only if the dependent cause is no addition in being to the cause it depends on. To be sure, it is often assumed that a tight enough connection like supervenience or necessitation is sufficient to guarantee that the necessitated or supervening entity is not something ontologically additional to the subvenient, or necessitating entity or entities. Hence Armstrong, who identifies supervenience with non-vacuous 
necessitation, ${ }^{19}$ says that "What supervenes is no addition of being [...] the supervenient is ontologically nothing more than its base" (1997, pp. 12-3). However, this is false. Non-vacuous necessitation, tight as it might be, is fully compatible with the necessitated fact being something 'over and above' the necessitating fact or facts (cf. Wilson 2012, pp. 9-12). In effect, the traditional test is too weak to separate causal instances that involve harmful overdetermination from those that don't. To see this, consider Bennett's thought experiment aimed at those who think that the ubiquitous nature of mental-physical overdetermination somehow makes it less troublesome because it gives us reason to think that it is not a coincidence:

Imagine, if you will, a world in which everything works just the way we like to think it actually does, with genuine causation and everything, except that unlike our world it also contains a meddling, Malebranchian god. This meddling god steps in and causes every effect, even though they already have causes that are both perfectly sufficient and perfectly mundane. Now, this is a world in which everything that happens has two distinct sufficient causes-one divine and one non-divine. The 'double-causing' is as pervasive as can be, and it is no coincidence. Yet it is also still overdetermination. Or so says my intuition, anyway (Bennett 2003, p. 475).

I think we should agree with this. More specifically, I think that we should agree that the 'double causing' in this case is both non-coincidental and harmful. But now, suppose that the meddling god is by its nature such that it acts consistently in every possible world so that for each mundane, earthly cause $[\mathrm{C}]_{\mathrm{e}}$, it is impossible for $[\mathrm{C}]_{\mathrm{e}}$ to obtain and for the corresponding divine cause $[\mathrm{C}]_{\mathrm{d}}$ not to obtain. If the above is an instance of harmful overdetermination that is non-coincidental, then arguably the same holds true here. For it is still the case in the world of evaluation that every mundane effect $[\mathrm{E}]_{\mathrm{e}}$ has a mundane cause and an additional divine cause. The only relevant difference between this case and the above is that there is a strong modal connection between $[\mathrm{C}]_{\mathrm{e}}$ and $[\mathrm{C}]_{\mathrm{d}}$. Yet, the traditional test would have you believe that this is not an instance of harmful overdetermination-this, since

$$
\mathrm{C}_{\mathrm{e}} \Rightarrow \operatorname{ch}\left(\mathrm{E}_{\mathrm{e}}\right)=p
$$

comes out vacuous in the absence of $[\mathrm{C}]_{\mathrm{d}}$ for some $p$ such that $p>\operatorname{ch}\left(\mathrm{E}_{\mathrm{e}}\right)$ would have been had $[\mathrm{C}]_{\mathrm{e}}$ not obtained. But since the divine cause is an ontological addition to the earthly cause, each earthly effect would still be harmfully overdetermined.

To this one might object that the claim that $[\mathrm{C}]_{\mathrm{d}}$ supervenes on $[\mathrm{C}]_{\mathrm{e}}$ does not readily square with the commonly held view that the meddling Malebranchian god could have decided to not cause $[\mathrm{E}]_{\mathrm{e}}$ despite the presence of $[\mathrm{C}]_{\mathrm{e}}$. If so, then the divine cause will not be necessitated by the mundane cause. But cases illustrating that necessitation is compatible with over-and-aboveness are not restricted to the divine. Consider the more naturalistically respectable view of Moorean emergentism, according to which, mental facts and physical facts are equally fundamental but that the mental facts emerge from

19 An entity Q, Armstrong says, "supervenes upon entity $\mathrm{P}$ if and only if it is impossible that $\mathrm{P}$ should exist and Q not exist, where $\mathrm{P}$ is possible", where impossibility is taken in its strongest sense and possibility in its weakest sense. (Armstrong 1997, p. 11). 
the physical facts due to metaphysically necessary psycho-physical laws of nature (cf. Horgan 2006, p. 160; Wilson 2005, 2012, p. 9). In that case each physical fact would metaphysically necessitate a corresponding equally fundamental mental fact. The traditional test would deem the physical effects of emergent mental causes to be permissibly overdetermined. But again, this seems wrong because the mental causes would in each case be something 'over and above' the physical causes. And this sort of systematic overdetermination by two causes, one of which is an addition to the other, is still a harmful form of overdetermination. Or so says my intuition, anyway.

The grounding physicalist is in a much better position than the traditional nonreductive physicalist. For she can explain the innocuous nature of mental-physical causation by reference to the 'tightest' and 'ultimate' metaphysical connection of grounding (Fine 2001, pp. 15-6), which by its nature is such that if some collection of facts $\Delta$ grounds $[\mathrm{P}]$, then each fact in $\Delta$ is more fundamental than $[\mathrm{P}]$ and the latter fact is nothing in addition to the former facts. The grounding physicalist can thus avoid the exclusion problem by reference to the following principle:

Harmful Overdetermination. [E] is harmfully overdetermined by $[\mathrm{C}]$ and $\left[\mathrm{C}^{\prime}\right]$ only if $[[\mathrm{C}]$ causes $[\mathrm{E}]]$ and $\left[\left[\mathrm{C}^{\prime}\right]\right.$ causes $\left.[\mathrm{E}]\right]$ do not share a common fundamental ground.

Conversely, if the fact that $[\mathrm{C}]$ causes $[\mathrm{E}]$ and the fact that $\left[\mathrm{C}^{\prime}\right]$ causes $[\mathrm{E}]$ share a common fundamental ground, then $[\mathrm{E}]$ is not harmfully overdetermined by $[\mathrm{C}]$ and $\left[\mathrm{C}^{\prime}\right]$. This explains why mental-physical causal overdetermination is permissible. For in those cases where a mental fact is grounded by some physical fact, the transitivity of grounding guarantees that they share the same fundamental ground. ${ }^{20}$ By combining Dual Causation with the transitivity of grounding, we thus get the desirable result that if some mental fact $[\mathrm{C}]_{\mathrm{m}}$ causes some physical fact $[\mathrm{E}]_{\mathrm{p}}$, then there is a physical fact $[C]_{p}$ such that the fact that $[C]_{m}$ causes $[E]_{p}$ and the fact that $[C]_{p}$ causes $[E]_{p}$ share the same exact fundamental ground. In view of Harmful Overdetermination, it follows that $[\mathrm{E}]_{\mathrm{p}}$ is not harmfully overdetermined by $[\mathrm{C}]_{\mathrm{m}}$ and $[\mathrm{C}]_{\mathrm{p}}$. Thus, even though $[\text { WINCE }]_{\mathrm{p}}$ is overdetermined by $[\mathrm{PAIN}]_{\mathrm{m}}$ and $[\mathrm{C}-\mathrm{FIBER}]_{\mathrm{p}}$, it is not a harmful form of overdetermination, since (6) and (7) are both fundamentally grounded by a complexity consisting of $[\text { pain }]_{\mathrm{p}}$, $[\text { wince }]_{\mathrm{p}}$ and whatever the facts are that make both the fact that Bill is in pain and the fact that his $\mathrm{C}$-fibers are firing raise the chance of the fact that Bill winces. Neither of these causal facts is anything 'over and above' the fundamental facts and so, is not an addition in being to the facts occupying the fundamental level of reality. ${ }^{21}$

\footnotetext{
${ }^{20}$ Let $[\mathrm{C}]_{\mathrm{m}}$ be some mental fact and $[\mathrm{C}]_{\mathrm{p}}$ some physical fact such that $[\mathrm{C}]_{\mathrm{p}}$ grounds $[\mathrm{C}]_{\mathrm{m}}$. By assumption there is some fundamental physical fact $[c]_{p}$ that grounds $[\mathrm{C}]_{\mathrm{p}}$. Since grounding is transitive, it follows that $[c]_{\mathrm{p}}$ also grounds $[\mathrm{C}]_{\mathrm{m}}$. Notice that when either the physical cause or the physical effect is fundamental, the common fundamental ground for the corresponding causal facts will be the same as in those cases where both the physical cause and the physical effect are non-fundamental. As long as the latter facts are grounded in the former facts, the shared fundamental ground in each of the above cases will be $[c]_{\mathrm{p}},[e]_{\mathrm{p}}$ and whatever the fundamental physical facts are that make the cause raise the chance of the effect. See fn. 13.

${ }^{21}$ Proponents of supervenience based non-reductivism could argue for something similar to Harmful Overdetermination by allowing for supervenience to hold between facts and by identifying a fundamental base fact with a fact that does not supervene on any other fact. For one could then present the following principle:
} 
Compare this with the independent rock-throwing actions of Suzy and Bill. Both the fact that Suzy throws a rock and the fact that Bill throws a rock suffices in the relevant circumstances for the fact that the window breaks. However, since the fundamental facts that ground the corresponding causal facts involving Suzy and Bill are distinct (or so we may assume), the overdetermination in play differs radically from mental-physical overdetermination (cf. Mellor 1995, pp. 101-105). This is not to say that whenever two causal facts involving the same effect have different fundamental grounds, the effect is also harmfully overdetermined. After all, there are instances of causal overdetermination involving different fundamental grounds that are permissible. Sometimes these are of the mental-physical variety as, for example, when someone has the desire to move their arm and a simultaneous involuntary spasm causes it to move. However, such instances are few and far between. It is only when the two causes are systematically correlated that it becomes reasonable to ask for an explanation of what is seemingly a mere coincidence between two independent causes. And if no such explanation can be given, the overdetermination in question does indeed appear worrying (cf. Sider 2003, p. 722). But nothing like this goes on in the case of $[\mathrm{PAIN}]_{\mathrm{m}}$ and $[\mathrm{C}-\mathrm{FIBER}]_{\mathrm{p}}$. It is not a coincidence that $[\mathrm{PAIN}]_{\mathrm{m}}$ and $[\mathrm{C}-\mathrm{FIBER}]_{\mathrm{p}}$ are correlated, as the latter grounds the former. But if this is so and the present theory is correct, then although $[\text { WINCE }]_{\mathrm{p}}$ is causally overdetermined by $[\mathrm{PAIN}]_{\mathrm{m}}$ and $[\mathrm{C}-\mathrm{FIBER}]_{\mathrm{p}}$, it is a permissible kind of overdetermination.

It is also of interest to notice that standard arguments against overdetermination do not apply. Such arguments enjoy wide support in the literature-being manifestations of the Occamian idea that once sufficient causation has been established the necessity is eclipsed and what goes beyond that is mere excess baggage (Kim 1989, p. 98). On the present theory, however, there is no excess baggage involved in mental-physical causation. By admitting [P] we are only ontologically committed to [P]'s fundamental ground (see Sect. 3.). In view of a true causal (CF), this means that our ontological commitments are to just those fundamental facts that ground the fact that $[\mathrm{C}]$ causes [E]. There is no requirement that we in addition to these fundamental grounds include into the ontology sui generis types of entities that correlate with the stated causes in either of (6) or (7). The causal facts, when they obtain, commit us only to [pain $]_{\mathrm{p}}$,

\section{Footnote 21 continued}

Supervenience Based Harmful Overdetermination. [E] is harmfully overdetermined by $[\mathrm{C}]$ and [C'] only if $[[\mathrm{C}]$ causes $[\mathrm{E}]]$ and [[C'] causes [E]] do not supervene on the same fundamental base fact(s).

Notice, however, that two facts sharing a common fundamental base fact (or facts) is fully compatible not only with the supervenient facts being ontologically additional to one another, but also the supervenient facts being ontologically additional to the fundamental base fact(s). This means that a principle that specifies a necessary condition on harmful overdetermination in terms of supervenience is bound to fail.

Consider the view of Moorean emergentism discussed above. Let $[\mathrm{C}]_{\mathrm{p}}$ be some physical cause and $[\mathrm{C}]_{\mathrm{m}}$ some equally fundamental mental cause such that $[\mathrm{E}]_{\mathrm{p}}$ is caused by both $[\mathrm{C}]_{\mathrm{p}}$ and $[\mathrm{C}]_{\mathrm{m}}$. Let us furthermore assume that $[\mathrm{C}]_{\mathrm{m}}$ supervenes on $[\mathrm{C}]_{\mathrm{p}}$ due to metaphysically necessary psycho-physical laws of nature and that there is a shared common fundamental base fact upon which both $\left[[\mathrm{C}]_{\mathrm{m}}\right.$ causes $\left.[\mathrm{E}]_{\mathrm{p}}\right]$ and $\left[[\mathrm{C}]_{\mathrm{p}}\right.$ causes $\left.[\mathrm{E}]_{\mathrm{p}}\right]$ supervene. According to Supervenience Based Harmful Overdetermination, this suffices to establish that $[\mathrm{E}]_{\mathrm{p}}$ is not harmfully overdetermined by $[\mathrm{C}]_{\mathrm{p}}$ and $[\mathrm{C}]_{\mathrm{m}}$. But the fact that $\left[[\mathrm{C}]_{\mathrm{m}}\right.$ causes $\left.[\mathrm{E}]_{\mathrm{p}}\right]$ and $\left[[\mathrm{C}]_{\mathrm{p}}\right.$ causes $\left.[\mathrm{E}]_{\mathrm{p}}\right]$ share a common fundamental base fact is fully compatible with $[\mathrm{C}]_{\mathrm{m}}$ being ontologically additional to $[\mathrm{C}]_{\mathrm{p}}$ and the causal facts, in turn, being additional to the fundamental base fact(s). According to the Moorean emergentist, the mental cause $i s$ ontologically additional to the physical cause. Thus, the mental cause and the physical cause will causally compete and $[\mathrm{E}]_{\mathrm{p}}$ is harmfully overdetermined by $[\mathrm{C}]_{\mathrm{p}}$ and $[\mathrm{C}]_{\mathrm{m}}$. I would like an anonymous referee for drawing my attention to this problem. 
[wince $]_{\mathrm{p}}$ and whatever the fundamental facts are that join with the laws of nature to raise the chance of the stated effect in the relevant circumstances $\mathrm{S}$. There is no further commitment to 'higher-level' entities that causally compete. To be sure, there are the facts in the liberal, uncontentious sense of 'fact' that Bill is in pain and that he winces. Unlike the fundamental facts, however, these are neither a burden to our ontology, nor are they entities made causally redundant by more fundamental facts-they are merely what $\langle$ Bill is in pain $\rangle$ and $\langle$ Bill winces $\rangle$ state is the case. ${ }^{22}$

To give a brief summary of this section: Grounding Physicalism together with the idea that grounded facts are nothing 'over and above' the facts that ground them yield a proliferation of causal instances in accordance with Dual Causation. This gives rise to a systematic form of overdetermination that renders Exclusion false. However, on the grounding physicalist picture, the overdetermination involved is of a particularly benign kind as the causal instances that render the effect overdetermined bottom out in a shared fundamental ground in accordance with Harmful Overdetermination. I thus conclude that grounding physicalism enables us to explicate the idea that we should appeal to a tight connection between the mental and the physical to account for the innocuous nature of mental-physical causation. I have also taken to show that neither supervenience nor metaphysical necessitation is up to the task - this, since modal covariation does not exhibit directionality and is fully compatible with the supervenient or necessitated fact being an ontological addition to the subvenient/necessitating fact (or facts). This means that the traditional non-reductivist is committed to viewing instances involving two or more equally fundamental causes, between which there is a modal connection, as being instances of a systematic but permissible form of overdetermination. But this, I have argued, is wrong. To account for the innocuous nature of mental-physical causation, we also need the dependent mental cause to not add to the being of the physical cause it depends on. Neither supervenience nor metaphysical necessitation is able to guarantee such intimacy (Wilson 2012, p. 9), which is why these notions are useless in determining whether a particular effect is harmfully overdetermined or not.

Still, I take it that there are those who are not convinced by the alleged merits of grounding physicalism over traditional supervenience physicalism. There are, as far as I can see, two concerns. One is how to square externalism about the mental with Grounding Physicalism; the other is how to square the innocuous nature of grounded facts with the possibility that physical facts could exist in the absence of the mental facts they ground.

\footnotetext{
22 This view should be distinguished from what Karen Bennett calls flatworldism, the view that "nothing is built, that there are no nonfundamentalia, that everything is absolutely fundamental" (Bennett 2017, p. 214). The view defended here is not as extreme as flatworldism in that as long as the propositions that affirm the existence of non-fundamentalia are true, it takes them to state facts. What the present view denies is that truths about non-fundamentalia, in any shape or form, reflect an ontology of levels of facts other than in the liberal, uncontentious sense of 'fact'.
} 


\section{Two potential concerns}

Let us consider the latter concern first. In the previous section, when addressing the standard test for overdetermination, I did not take a stand on whether grounds need to necessitate the facts they ground in the sense that if some collection of facts $\Gamma$ grounds $[\mathrm{P}]$, then there is no possible world in which $\Gamma$ obtains but $[\mathrm{P}]$ does not. The orthodoxy is grounding necessitarianism, i.e. the view that there cannot be grounding without necessitation. My own view is that the orthodoxy is false (Stenwall 2016, 2017), and thus that there are non-vacuous counterfactuals whose antecedents state a physical fact, but that they are all false in the absence of the mental facts they ground. I will not argue this point further. Suffice it for present purposes to say that one of the strengths of the present theory is that it is compatible with both grounding necessitarianism and contingentism. This might initially seem strange. Prima facie, a denial of grounding necessitarianism is incompatible with the view that grounded facts are 'nothing over and above' the facts that ground them. After all, if $[\mathrm{C}]_{\mathrm{p}}$ can obtain in the absence of $[\mathrm{C}]_{\mathrm{m}}$ it would appear that the mental fact is a further fact 'over and above' the physical fact in that there is some additional condition that $[\mathrm{C}]_{\mathrm{p}}$ needs to fulfil for $[\mathrm{C}]_{\mathrm{m}}$ to obtain.

Fortunately, there is an easy way to fix this problem. For just as causes are not sufficient for their effects simpliciter, some facts are not grounded in more fundamental facts simpliciter, but rather under a specific set of circumstances. Take, for example, an accidental general fact, like the fact that all men are mortal. Russell (1956, p. 236) showed that no enumeration of mortal men-no collection of facts consisting of $\left[a_{1}\right.$ is a mortal man], [ $a_{2}$ is a mortal man $], \ldots\left[a_{\mathrm{n}}\right.$ is a mortal man] necessitates the fact that all men are mortal (even if all men are included in the collection). The large collection of mortal men will only ground [all men are mortal] in circumstances like the actual where there are no men in addition to $a_{1}, a_{2}, \ldots a_{\mathrm{n}}$. In other possible worlds in which this collection exists, the presence of some immortal man will make it a fact that not all men are mortal. Such is the nature of accidental general facts. Now, by taking grounding to be contingent on the circumstances in which the grounding takes place, nothing-over-and-above-talk can be made compatible with a denial of grounding necessitarianism, since some particular fact $[\mathrm{P}]$ might be nothing 'over and above' some collection of facts $\Gamma$ under a specific set of circumstances and yet, despite the presence of $\Gamma,[\mathrm{P}]$ might not obtain in a different set of circumstances (see e.g. Skiles (2015) for further examples of this kind). ${ }^{23}$ This is important because it enables the grounding physicalist to avoid a potential externalist threat.

\footnotetext{
23 I don't take it to be a necessary condition of a full ground that it metaphysically necessitates what it grounds (see Sect. 2.). So that $\Gamma$ obtains and $[\mathrm{P}]$ does not is fully compatible with $\Gamma$ being $[\mathrm{P}]$ 's full ground. To this one might object that the collection of mortal does not ground [all men are mortal] unless there are no men in addition to $a_{1}, a_{2}, \ldots a_{\mathrm{n}}$. Thus, the thought goes, the collection of men must somehow be supplemented with [there are no men in addition to $a_{1}, a_{2}, \ldots a_{\mathrm{n}}$ ] in order to yield the full ground for [all men are mortal]. But this clearly begs question against the grounding contingentist (Stenwall 2016). As noted by Alexander Skiles, the inference also fails in corresponding cases in which a collection of facts causally brings about an accidental generalization (Skiles 2015, p. 732). But if so, it is hard to see why it would be valid when a collection of facts non-causally brings about an accidental generalization unless further substantial argument is provided. Moreover, "it does not follow in general that if $\Gamma$ does not ground $[\mathrm{P}]$ unless the facts in $\Gamma$ have a certain feature, then they must be supplemented by the fact that these facts have that feature" in order to yield a ground for [P] (Skiles 2015, p. 732). Thus, for example, a necessary
} 
Again, consider Dual Causation, which—as already argued—is a consequence of Grounding Physicalism and the innocuous nature of grounding. Michael Clark and Nathan Wildman (2018) have recently argued that Dual Causation is false on the grounds that there seem to be instances where a mental fact causes a physical fact, but where the physical grounds of the former do not cause the latter. To take an example, consider the fact that Bill desires to drink water and that he believes that there is a glass of water in front of him (call the corresponding conjunctive fact '[WATER] $]_{\mathrm{m}}$ '). Now, suppose that:

(9) $[\mathrm{WATER}]_{\mathrm{m}}$ causes $[\mathrm{DRINK}]_{\mathrm{p}}$,

where the latter is the fact that Bill drinks the water. Dual Causation predicts that there is some physical fact $[\mathrm{C}]_{\mathrm{p}}$ such that $[\mathrm{C}]_{\mathrm{p}}$ both grounds $[\mathrm{WATER}]_{\mathrm{m}}$ and causes $[\mathrm{DRINK}]_{\mathrm{p}}$. But it seems to get the prediction wrong. Externalist considerations like those made famous by Burge (1979) and McGinn (1989), suggest that the full physical ground for $[\mathrm{WATER}]_{\mathrm{m}}$ will include, in addition to various internal physical facts about Bill's brain, also whatever the external physical facts are that ground the causal, social and historical facts that explain why Bill's thought is about water $\left(\mathrm{H}_{2} \mathrm{O}\right)$ rather than, say, twin-water (XYZ). But since these facts are spatiotemporally distributed across Bill's surroundings, there is no reason to expect that [WATER $]_{m}$ 's physical ground will be causally related to $[\mathrm{DRINK}]_{\mathrm{p}}$ in the systematic manner predicted by Dual Causation (Clark and Wildman 2018, p. 3731). Consequently, there seem to be cases where a mental fact $[\mathrm{C}]_{\mathrm{m}}$ causes a physical fact $[\mathrm{E}]_{\mathrm{p}}$ but where $[\mathrm{C}]_{\mathrm{m}}$ 's physical ground is unfit to cause $[\mathrm{E}]_{\mathrm{p}}$ - thus countering the prediction.

The most obvious response to the externalist threat is to make a distinction between broad and narrow content beliefs, and then argue that only narrow content beliefs are causally efficacious (cf. Fodor 1987). This allows for an argument to the conclusion that grounds for beliefs are intrinsic to the believer and as such, suitable to bring about the same effects as the corresponding narrow content beliefs. On this view, (9) is false. What causes $[\mathrm{DRINK}]_{\mathrm{p}}$ is not $[\mathrm{WATER}]_{\mathrm{m}}$ but, rather, $[\mathrm{N}-\mathrm{WATER}]_{\mathrm{m}}$, where the latter is the relevant narrow content surrogate for $[\mathrm{WATER}]_{\mathrm{m}}$. Since the physical ground for $[\mathrm{N}-\mathrm{WATER}]_{\mathrm{m}}$ only depends on Bill's internal make-up, it will slot more readily into [N-WATER $]_{\mathrm{m}}$ 's causal role (Clarke and Wildman 2018, p. 3731).

There are, however, several problems with this line of response. The notion of narrow content is highly contentious. Intrinsic duplicates have the same narrow mental content by virtue of instantiating the same function from contexts of thought to the broad content their mental states have in those contexts. Saidel (1994) and others have argued that this begs the question against the externalist by assuming that it is possible for intrinsic duplicates to have the same belief in different contexts. There are even those who, like Adams et al. (1990), think that the very notion of narrow content is incoherent and not suited to do the job for which it was intended. More alarming, however, is the fact that even if we assume that the notion of narrow content makes sense, broad content descriptions play an essential role in cases like the above where the cause suffices for a behavioural effect that is characterized in broad terms.

Footnote 23 continued

condition for $[\mathrm{P}]$ and $[\mathrm{Q}]$ to ground $[\mathrm{P} \& \mathrm{Q}]$ is that $[\neg \mathrm{P}]$ and $[\neg \mathrm{Q}]$ not obtain. But it does not follow that $[\mathrm{P}]$ and $[\mathrm{Q}]$ be supplemented with $[[\neg \mathrm{P}]$ and $[\neg \mathrm{Q}]$ do not obtain] to ground the conjunctive fact: $[\mathrm{P}]$ and $[Q]$ suffice. I would like to thank an anonymous referee for bringing my attention to these points. 
The characterization of the physical effect as the fact that Bill drinks the water is not capricious, but is the very one under which he intended when he drank from the glass, and is therefore the one we should use when we want to explain how the glassdrinking-action makes sense from Bill's point of view (Williamson 1995, p. 548). But if the relevant effect is the fact that Bill drinks the water $\left(\mathrm{H}_{2} \mathrm{O}\right)$, the cause that suffices for $[\mathrm{DRINK}]_{\mathrm{p}}$ is not $[\mathrm{N}-\mathrm{WATER}]_{\mathrm{m}}$, but rather $[\mathrm{WATER}]_{\mathrm{m}}$. For on TwinEarth, Bill's intrinsic duplicate Twin-Bill—having the same narrow content belief as Bill on Earth-drinks the twin-water (XYZ) (Yablo 1992; see also Clark and Wildman 2018, p. 3732). Consequently, and contrary to the traditional internalist picture, narrow content beliefs do not causally suffice for the relevant effects.

What I take the above to suggest is that just like it is in the nature of accidental general facts that the grounding of them is contingent on external circumstances, it is also in the nature of broad mental facts that the grounding of them is contingent on external factors. ${ }^{24}$ This insight enables us to remain externalists with respect to mental content without having to give up on Dual Causation. To see this, suppose that (9) is true. We thus get that there is some physical fact that grounds [WATER $]_{m}$ and causes $[\mathrm{DRINK}]_{\mathrm{p}}$. However, there is no reason in particular why we should supplement [WATER $]_{m}$ 's physical ground with the various external facts that make Bill's thought about water rather than twin-water. As a matter of fact, one would have thought precisely the opposite, since there are reasons to think that grounding is a local and non-diachronic affair (Bernstein 2016; Trogdon 2018). ${ }^{25}$ And if it is, (as I'm inclined to think) then the facts that make up Bill's causal history is not to be included in whatever it is that grounds [WATER $]_{\mathrm{m}}$. This is not to say that we can only provide grounds for narrow content beliefs or that beliefs characterized in broad terms remain ungrounded. For, in view of the above, we can now say that it is in the nature of broad mental facts, like it is in the nature of accidental general facts, that they are never grounded simpliciter, but always under a specific set of circumstance. In the case of broad mental facts, these circumstances are those physical circumstances that must hold for the mental fact to cause the physical fact (see $\$ 4$; see also Bennett 2003 , p. 488). Thus, what physically grounds [WATER $]_{m}$ is not some spatiotemporally scattered entity involving the intrinsic physical state of Bill taken together with various external facts involving Bill's past interactions with water $\left(\mathrm{H}_{2} \mathrm{O}\right)$. Rather, what grounds [WATER $]_{\mathrm{m}}$ is an internal fact about Bill, like the fact that he is in a certain brain state $\phi$ (call it '[BRAIN $\phi]_{\mathrm{p}}$ '). In circumstances $\mathrm{S}$ ', like those found on Twin-Earth, [BRAIN $\phi]_{p}$ provides a physical ground for the fact that Bill thinks about twin-water (XYZ), whereas in the relevant circumstances $S$, like those found here on Earth, [BRAIN $\phi]_{\mathrm{p}}$ will physically (and synchronically) ground [WATER $]_{\mathrm{m}}$. But if so, it follows in accordance with Dual Causation that:

\section{$[\operatorname{BRAIN} \phi]_{\mathrm{p}}$ causes $[\mathrm{DRINK}]_{\mathrm{p}}$}

\footnotetext{
24 I will leave it open whether there are facts other than accidental general facts and broad mental facts that are context sensitive in this sense. Although I will not discuss this further, there are reasons to think that negative facts will exhibit a similar context sensitivity as general facts due to their similar nature (cf. Armstrong 2004, pp. 53-82).

25 Although, see (Wilson 2018) for the view that grounding isn't synchronic.
} 
in S. And similarly for all other mental facts characterized in broad terms. We are thus in the fortunate position that we can remain externalists with respect to mental content while simultaneously holding on to Grounding Physicalism and the idea that grounded facts are nothing 'over and above' the facts that ground them.

\section{Concluding remarks}

I have argued that the grounding physicalist can solve the exclusion problem by rejecting Exclusion, i.e. the claim that physical effects of mental facts are not systematically overdetermined. They are. But it is a particularly benign form of systematic overdetermination that not only is not harmful but also compatible with the externalist picture of the mental. In arguing this, I've traded heavily on an account of causation in terms of fundamental facts and the elusive, but intuitive notion of nothing-overand-aboveness-which I took to be explicated in terms of not being additions to the being of fundamental facts. My intention has been entirely programmatic in that I have merely wanted to sketch the broad outlines of a solution to a problem where I think the notion of grounding has the potential to shed new light. Much more needs to be done to further elucidate and specify what is meant by one fact being nothing 'over and above' another fact (or facts); to see whether the notion of ground has the potential to close the explanatory gap between the phenomenal and the physical (Levine 2001; Schaffer 2017; Trogdon 2018); and so forth. These are, of course, questions that we expect the grounding physicalist to provide comprehensive answers to in due course. Until then, we can rest assured that there will be much more to discuss about the expected utility of grounding physicalism for the problem of mental causation.

Acknowledgements I'd like to thank Alexander Skiles, Anna-Sofia Maurin, Darragh Byrne, Kelly Trogdon, Naomi Thompson and Andrew Brenner for their insightful comments on an earlier version of this paper. I would also like to thank the anonymous referees for their helpful comments. This work is supported by Riksbankens Jubileumsfond [Grant Number P16-0541:1].

Funding Open access funding provided by Lund University.

Open Access This article is licensed under a Creative Commons Attribution 4.0 International License, which permits use, sharing, adaptation, distribution and reproduction in any medium or format, as long as you give appropriate credit to the original author(s) and the source, provide a link to the Creative Commons licence, and indicate if changes were made. The images or other third party material in this article are included in the article's Creative Commons licence, unless indicated otherwise in a credit line to the material. If material is not included in the article's Creative Commons licence and your intended use is not permitted by statutory regulation or exceeds the permitted use, you will need to obtain permission directly from the copyright holder. To view a copy of this licence, visit http://creativecommons.org/licenses/by/4.0/.

\section{References}

Adams, F., Drebushenko, D., Fuller, G., \& Stecker, R. (1990). Narrow content: Fodor's Folly. Mind and Language, 5(3), 213-229.

Armstrong, D. M. (1997). A world of states of affairs. Cambridge: Cambridge University Press. Armstrong, D. M. (2004). Truth and truthmakers. Cambridge: Cambridge University Press. 
Audi, P. (2012). A clarification and defense of the notion of grounding. Correia and Schnieder, 2012, $101-121$.

Bennett, K. (2003). Why the exclusion problem seems intractable, and how, just maybe, to tract it. Noûs, 37(3), 471-497.

Bennett, K. (2011). By our bootstraps. Philosophical Perspectives, 25, $27-41$.

Bennett, K. (2017). Making things up. Oxford: Oxford University Press.

Bernstein, S. (2016). Grounding is not causation. Philosophical Perspectives, 30, 21-38.

Blackburn, S. (1984). Spreading the word. Oxford: Clarendon.

Bohn, E. D. (2018). Indefinitely descending ground. In R. Bliss \& G. Priest (Eds.), Reality and its structure: Essays in fundamentality (pp. 167-181). New York: Oxford University Press.

Burge, T. (1979). Individualism and the mental. In P. A. French, T. E. Uehling, \& H. K. Wettstein (Eds.), Midwest studies in philosophy (Vol. 4, pp. 73-121). Minneapolis: University of Minnesota Press.

Cameron, R. (2008). Truthmakers and ontological commitment. Philosophical Studies, 140(1), 1-18.

Cameron, R. (2010). How to have a radically minimal ontology. Philosophical Studies, 151(2), $249-264$.

Clark, M., \& Wildman, N. (2018). Grounding, mental causation, and overdetermination. Synthese, 195(8), 3723-3733.

Correia, F., \& Schnieder, B. (Eds.). (2012). Metaphysical rounding: Understanding the structure of reality. Cambridge: Cambridge University Press.

Dasgupta, S. (2014). The possibility of physicalism. Journal of Philosophy, 111, 557-592.

Fine, K. (1994). Essence and modality. Philosophical Perspectives, 8, 1-16.

Fine, K. (2001). The question of realism. Philosophers' Imprint, 1, 1-30.

Fine, K. (2010). Some puzzles of ground. Notre Dame Journal of Formal Logic, 51(1), 97-118.

Fine, K. (2012). Guide to ground. In F. Correia \& B. Schnieder (Eds.), Metaphysical grounding: Understanding the structure of reality (pp. 37-80). Cambridge: Cambridge University Press.

Fodor, J. (1987). Psychosemantics. Cambridge: MIT Press.

Heil, J. (2003). From an ontological point of view. Oxford: Oxford University Press.

Heil, J. (2012). The universe as we find it. Oxford: Oxford University Press.

Heil, J., \& Mele, A. R. (Eds.). (1993). Mental causation. New York: Clarendon Press/Oxford University Press.

Horgan, T. (2006). Materialism: Matters of definition, defense and deconstruction. Philosophical Studies, 131(1), 157-183.

Kim, J. (1989). Mechanism, purpose, and explanatory exclusion. Philosophical Perspectives, 3, 77-108. (Reprinted in Kim 1993a, pp. 237-64).

Kim, J. (1993a). Supervenience and mind: Selected philosophical essays. Cambridge: Cambridge University Press.

Kim, J. (1993b). The non-reductivist's troubles with mental causation. In J. Heil \& A. R. Mele (Eds.), Mental causation (pp. 189-210). Oxford: Clarendon Press. (Reprinted in Kim (1993a). pp. 336-57).

Kim, J. (1998). The mind-body problem after fifty years. In A. O'Hear (Ed.).

Kim, J. (2005). Physicalism, or something near enough. Princeton: Princeton University Press.

Kovacs, D. M. (forthcoming). Four questions of iterated grounding. Philosophy and Phenomenological Research.

Krämer, S. (2013). A simpler puzzle of ground. Thought, 2(2), 85-89.

Kroedel, T., \& Schulz, M. (2016). Grounding mental causation. Synthese, 193(6), 1909-1923.

Lepore, E., \& Loewer, B. M. (1987). Mind matters. Journal of Philosophy, 84, 630-642.

Levine, J. (2001). Purple haze. Oxford: Oxford University Press.

Lewis, D. (2000). Causation as influence. The Journal of Philosophy, 97, 182-197.

Litland, J. E. (2013). On some counterexamples to the transitivity of grounding. Essays in Philosophy, 14, 19-32.

Litland, J. E. (2017). Grounding ground. In K. Bennett \& D. Zimmerman (Eds.), Oxford studies in metaphysics (Vol. 10, pp. 279-315). Oxford: Oxford University Press.

McGinn, C. (1989). Mental content. Oxford: Blackwell.

McGinn, C. (1993). Problems in philosophy: the limits of inquiry. Cambridge: Basil Blackwell.

Mellor, D. H. (1995). The facts of causation. London: Routledge Press.

Mills, E. (1996). Interactionism and overdetermination. American Philosophical Quarterly, 33, $105-117$.

O'Hear, A. (Ed.). (1998). Current issues in philosophy of mind. Cambridge: Cambridge University Press.

Pietroski, P. M. (1994). Mental causation for dualists. Mind and Language, 9, 336-366.

Raven, M. J. (2013). Is ground a strict partial order? American Philosophical Quarterly, 50(2), 191-199. 
Rodriguez-Pereyra, G. (2005). Why truthmakers? In H. Beebee \& J. Dodd (Eds.), Truthmakers: The contemporary debate (pp. 17-31). Oxford: Oxford University Press.

Rodriguez-Pereyra, G. (2015). Grounding is not a strict order. Journal of the American Philosophical Association, 1(3), 517-534.

Russell, B. (1956). The philosophy of logical atomism. In Logic and Knowledge, London: Allen \& Unwin.

Saidel, E. (1994). Discussion: Content and causal powers. Philosophy of Science, 61, 658-665.

Schaffer, J. (2008). Truth and fundamentality: On Merrick's truth and ontology. Philosophical Books, 49(4), 302-316.

Schaffer, J. (2012). Grounding, transitivity and contrastivity. Correia \& Schnieder, 2012, 122-138.

Schaffer, J. (2017). The ground between the gaps. Philosophers' Imprint, 7(11), 1-26.

Sider, T. (2003). What's so bad about overdetermination? Philosophy and Phenomenological Research, 67(3), 719-726.

Sider, T. (2011). Writing the book of the world. Oxford: Oxford University Press.

Skiles, A. (2015). Against grounding necessitarianism. Erkenntnis, 80(4), 717-751.

Stenwall, R. (2010). Causal truthmaking. Metaphysica, 11, 211-222.

Stenwall, R. (2016). Against truthmaker necessitarianism. Logique et Analyse, 59, 37-54.

Stenwall, R. (2017). Causal grounds for negative truths. Philosophical Studies, 174, 2973-2989.

Thompson, N. (2016). Metaphysical interdependence. In M. Jago (Ed.), Reality making (pp. 38-56). Oxford: Oxford University Press.

Trogdon, K. (2018). Grounding-mechanical explanation. Philosophical Studies, 175(6), 1289-1309.

Wallner, M. (forthcoming). The ground of ground, essence, and explanation. Synthese.

Williamson, T. (1995). Is knowing a state of mind? Mind, 104(415), 533-565.

Wilson, A. (2018). Metaphysical Causation. Noûs, 52(4), 723-751.

Wilson, J. (2005). Supervenience-based formulations of physicalism. Noûs, 39, 426-459.

Wilson, J. (2012). Fundamental determinables. Philosophers' Imprint, 12(4), 1-17.

Yablo, S. (1992). Mental causation. The Philosophical Review, 101(2), 245-280.

Publisher's Note Springer Nature remains neutral with regard to jurisdictional claims in published maps and institutional affiliations. 